\title{
PENDIDIKAN KARAKTER PERSPEKTIF ISLAM
}

(Studi Pemikiran KH. Abdul Wahid Hasyim)

\author{
Nindia Puspitasari \\ PG-SIT Kautsar Ilmi Prabumulih \\ nindia.puspitasari92@gmail.com
}

\begin{abstract}
This research is motivated by the importance of character education in Indonesia an Islamic perspective. Some things are a matter of concern is the declining values of character, it is marked by moral degradation of youth, ranging from fighting between students, drugs, violence, murder and others. Various attempts were made to address the moral decadence of the young generation, among whom was the launching of character education in environmental education, both formal and non-formal. This study is a literature study or (library research) by making the life history K.H Abdul Wahid Hashim and some works tulisanya as research objects. This study uses data collection techniques documentation. After doing research on the life history K.H Abdul Wahid Hasyim and some of his papers, produced two findings. First, there are twelve values of character education that seeks implanted K.H Abdul Wahid Hasyim. Twelve of these values are; religious values, the values of tolerance, the value of discipline, values of hard work, the value of an independent, democratic values, creative values, the value of the national spirit, the value of patriotism, the value of friends / communicative, fond of reading and the value of curiosity value. While both findings in this study, explained that the values of character education K.H Abdul Wahid Hasyim in line with the goal of character education. He sought to build a national life of a multicultural, build a civilization of intelligent, cultured noble, and capable of contributing to the development of human life, developing the potential of the base in order to be good, good thoughts, and behave well and exemplary good, to build a sense of citizenship that loves peace, creative, independent, and able to coexist with other nations in a harmony.
\end{abstract}

\section{Keyword: Character Education, KH. Abdul Wahid Hasyim's Thought}

\section{PENDAHULUAN}

Pendidikan di Indonesia hingga saat ini masih terus dibangun dan dikembangkan agar menghasilkan generasi bangsa yang diharapkan.Dalam rangka menghasilkan generasi bangsa yang diharapkan dan unggul, proses pendidikan senantiasa dievaluasi dan diperbaiki.Salah satu upaya perbaikan kualitas pendidikan adalah gagasan pendidikan karakter. Gagasan ini muncul karena proses pendidikan selama ini dinilai belum sepenuhnya berhasil dalam membangun manusia Indonesia yang berkarakter. Penilaian ini didasarkan pada lulusan sekolah dan sarjana yang cerdas secara intelektual, namun tidak bermental tangguh dan berprilaku sesuai dengan tujuan mulia pendidikan. ${ }^{1}$ Kondisi tersebut saat ini dapat dilihat dari banyaknya insana-insan

\footnotetext{
${ }^{1}$ Tujuan mulia Pendidikan Nsional adalah mengembangkan kemampuan dan membentuk watak serta peradaban bangsa yang bermartabat dalam rangka mencerdaskan bangsa.Lihat Undang-Undang Republik 
yang terdidik di negeri ini memiliki prilaku yang tidak sesuai dengan tujuan pendidikan.Misalnya tindak korupsi yang ternyata dilakukan oleh para pejabat politikus yang notabenya orang-orang berpendidikan.Mereka tanpa berdosa mengkorupsi uang rakyat sehingga berdampak pada kemiskinan di kalangan rakyatnya. ${ }^{2}$ Belum lagi tindak kekerasan yang akhir-akhir ini marak terjadi di negri ini, seperti ; anarkis, pembunuhan, tawuran antar pelajar bahkan antar mahasiswa, kasus narkoba dan kasus tindak asusila.

Lalu yang menjadi pertanyaan mendasar saat ini, apakah pendidikan itu hanya merupakan mesin yang menghasilkan manusia cerdas secara intelektual?. Tidak, pendidikan merupakan usaha sadar dan terencana untuk mewujudkan suasana belajar dan proses pembelajaran agar peserta didik secara aktif mengembangkan potensi diri untuk memiliki kekuatan spiritual keagamaan, pengendalian diri, kepribadian, kecerdasan, akhlak mulia, serta ketrampilan yang diperlukan dirinya, masyarakat bangsa dan negara. ${ }^{3}$ Pendidikan juga merupakan bimbingan atau pimpinan secara sadar oleh si pendidik terhadap perkembangan jasmani dan rohani si terdidik menuju terbentuknya kepribadian yang utama. ${ }^{4}$

Untuk membentuk manusia yang mulia dan bangsa yang bermartabat salah satu upaya yang dilakukan adalah melalui pendidikan karakter. Melalui pendidikan karakter tersebut diharapkan dunia pendidikan ${ }^{5}$ akan menjadi motor penggerak dalam membangun karakter peserta didik dan anggota masyarakat pada umumnya, sehingga memiliki kesadaran kehidupan berbangsa dan bernegara yang kuat, berakhlak, berprinsip dan bermartabat dengan mempertimbangkan norma-norma agama dan budaya masyarakat. Upaya ini menjadi pondasi utama dalam mensukseskan Indonesia di masa mendatang. ${ }^{6}$

Bangsa Indonsia saat ini memerlukan pendidikan karakter, ${ }^{7}$ yakni karakter yang bernafaskan nilai-nilai agama. ${ }^{8}$ Atau dengan kata lain (agama

Indonesia Nomor 20 Tahun 2003 Tentang Sistem Pendidikan Nasional Bab II Dasar, Fungsi, dan Tujuan Pasal 3. hlm. 9.

${ }^{2}$ Agus Wibowo, Pendidikan Karakter Berbasis Sastra, cet. ke-1 (Yogyakarta : Pustaka Pelajar, 2013),

${ }^{3}$ Undang-Undang Republik Indonesia Nomor 20 Tahun 2003 Tentang Sistem Pendidikan Nasional Bab 1 Ketentuan Umum Pasal 1 ayat 1.

${ }^{4}$ Akhmad D. Marimba, dalam Pengantar Filsafat Pendidikan Islam (Bandung : Al-Ma'arif, 1962), hlm. 19.

${ }^{5}$ Pendidikan bukan hanya sebagai wahana untuk mendidik anak didik menjadi cerdas semata, melainkan juga berkarakter.Sungguh, orang-orang yang berkarakter baik sangat dibutuhkan dalam membangun bangsa ini. Lihat di Akhmad Muhaimimin Azzet, Urgensi Pendidikan Karakter di Indonesia, cet.ke-II (Yogyakarta : Ar-Ruzz Media, 2013), hlm. 18.

${ }^{6}$ Ibid, hlm. 11-12.

${ }^{7}$ Sebenarnya yang diusung untuk dijadikan dasar dalam pendidikan karakter adalah nilai-nilai agama yang bersifat universal.Nilai-nilai universal agama yang dijadikan dasar dalam pendidikan karakter sangat penting karena keyakinan seseorang terhadap kebenaran nilai yang berasal dari agamanya bisa menjadi motivasi yang kuat untuk membangun karakter.Dalam hal penanaman nilai bangsa Indonesia memang sangat memerlukan model pendidikan semacam ini.Sebab pendidikan bukan hanya sebagai wahana untuk mendidik anak didik menjadi cerdas semata, melainkan juga berkarakter. Ibid.

${ }^{8}$ Pendidikan agama adalah pendidikan yang memberikan pengetahuan dan membentuk sikap, kepribadian, dan ketrampilan peserta didik dalam mengamalkan ajaran agamanya. Lihat di Peraturan 
Islam) yang merupakan Pendidikan Islam Berbagis Karakter.Untuk itu dalam kajian penelitian ini, penulis berusaha menggali salah satu tokoh yang memiliki peranan besar terhadap pencerahan dalam dunia pendidikan.Beliau adalah seorang intelektual muda pesantren dan tokoh NU, tokoh yang getol menanamkan nilai-nilai agama dalam pendidikan yakni KH. Abdul Wahid Hasyim, putra kelima dari pasangan KH. Hasyim Asy'ari pendiri jami'iyah NU dengan Nyai Nafiqah binti Kyai Ilyas, yang mempunyai silsilah sampai pada Sultan Brawijaya VI baik dari jalur ayah maupun ibu. ${ }^{9}$ Anak lelaki pertama dari 10 bersaudara ini, lahir pada hari Jumat legi, 5 Rabiul Awwal 1333 H, bertepatan dengan 1 Juni $1914 \mathrm{M}$, ketika di rumahnya sedang ramai dengan pengajian. ${ }^{10}$

Sebagai anak seorang tokoh terkemuka, KH.Abdul Wahid Hasyim tidak pernah mengenyam pendidikan di bangku sekolah pemerintahan Hindia Belanda.Dia lebih banyak belajar secara outodidak atau mandiri. Saat berusia 5 tahun, ia belajar membaca al-Qur'an pada ayahnya (Hadratus Syaikh Hasyim As'ari) di madrasah salafiah Tebuireng. Selain belajar di pondok pesantren dan madrasah, ia juga banyak mempelajari sendiri kitab-kitab dan buku berbahasa Arab. Dengan karakter ia yang gemar dalam membaca, ia juga mendalami syairsyair berbahasa Arab hingga hapal di luar kepala, dan menguasai maknanya dengan baik. ${ }^{11}$ Masa mudanya KH. Abdul Wahid Hasyim banyak dihiasi dengan pengembaraan ilmu di pesantren, di antaranya : Pesantren Tebuireng milik ayahnya sendiri, Pesantren Siwalan Panji, dan Lirboyo. Seperti halnya tokohtokoh besar pada masanya, tujuan dari pengembaraan ilmu tersebut tidak lain adalah untuk mencari barokah dari sang guru. Karena banyak catatan dari aktivitas pendidikan K.H Abdul Wahid Hasyim sering berpindah tempat. ${ }^{12}$

Kiprah KH. Abdul Wahid Hasyimdiawali dari pondok pesantren Tebuireng, yakni dengan menjadi staf pengajar di Tebuireng.Dia mulai mengadakan revolusi dalam dunia pendidikan pesantren.KH. Abdul Wahid Hasyim ingin mencoba dan memberi sumbangan dalam hal pembaruan pendidikan, dengan percobaan metode baru yang terdiri dari penggabungan ilmu agama Islam dan pengetahuan umum. Hal itu di lakukan untuk kemajuan dunia pesantren.Ia tidak ingin melihat lagi para santri lebih rendah kedudukannya dalam masyarakat dari pada kaum terpelajar Barat. Dari pengalaman menurutnya kekurangan-kekurangan itu hanya terdapat dalam ilmu pengetahuan umum. ${ }^{13}$

Pemerintah Republik Indonesia Nomor 55 Tahun 2007 Tentang Pendidikan Agama dan Keagamaan Bab 1 Ketentuan Umum Pasal 1 ayat 1.

${ }^{9}$ Silsilah dari jalur ayah KH. Abdul Wahid Hasyim bersambung hingga Joko Tingkir, tokoh yang dikenal dengan nama Sultan Sutawijaya yang berasal dari kerajaan Islam Demak, sedangkan dari pihak ibu, silsilah bersambung hingga Ki Ageng Tarub I, bila ditarik lebih jauh, kedua silsilah itu bertemu pada satu titik, yaitu Sultan Brawijaya VI, yang menjadi salah satu Raja Kerajaan Mataram. Sultan Brawijaya VI dikenal dengan sebutan Lembu Peteng.Lebih lengkapnya lihat di Aboebakar Atjeh, Sejarah Hidup KH.Abdul. Wahid Hasyim (Jombang Jawa Timur : Pustaka Tebuireng, 2015), hlm. 155-156.

${ }^{10}$ Muhammad Rifa'I, Wahid Hasyim Biografi Singkat 1914-1953, cet. ke 1 (Yogyakarta : Ar-Ruzz Media Group, 2009), hlm. 17.

${ }^{11}$ Ibid,.hlm. 22-23.

${ }^{12}$ Ibid,.hlm. 23.

${ }^{13} \mathrm{Ibid},$. hlm. $169-171$. 
Setelah percobaan metode baru tersebut berhasil, kemudian pada tahun berikutnya, yaitu tahun 1935 KH.Abdul Wahid Hasyim mulai membuka besarbesaran madrasah modern, yang dinamakan Madrasah Nidzamiyah, suatu perguruan hasil ciptaan K.H. Abdul Wahid Hasyim sendiri.Madrasah tersebut sebagai pelopor lembaga pendidikan Islam yang mampu mensinergikan antara pendidikan umum dengan pendidikan Islam. ${ }^{14}$ Kemudian puncak kariernya pada masa RIS dan Republik Kesatuan, KH Abdul Wahid Hasyim terpilih sebagai Mentri Agama dalam tiga periode, yaitu dalam Kabinet Hatta (20 Desember 1949 - 6 Desember 1950), dalam Kabinet Natsir mulai (6 September 1950 - 27 April 1951) dan dalam Kabinet Sukiman mulai (27 April 1951 - 3 April 1952). Pada tahun-tahun berikutnya, KH.Abdul Wahid Hasyim mengeluarkan tiga buah keputusan yang mempengaruhi sistem pendidikan di Indonesia. ${ }^{15}$ Dipuncak karir KH.Abudul Wahid Hasyim tersebut gagasan-gagasannya banyak diabadikan dalam tulisan-tulisannya sebagai Mentri Agama. Dari berbagai macam tema tulisan tersebut, yang penulis jadikan acuan dalam penelitian, diantarnya :

a. Nabi Muhammad dan Persaudaraan Manusia,yang merupakan pidatonya pada acara pembukaan Perayaan Maulid Nabi Muhammad Saw yang diadakan di Istana Negara, Jakarta pada 2 Januari 1950, dan merupakan perayaan Maulid pertama sesudah penyerahan kedaulatan Republik Indonesia. ${ }^{16}$

b. Kebangkitan Dunia Islam, karya ini merupakan tulisannya dimedia Mimbar Agama, No 3-4, Maret-April 1951. ${ }^{17}$

c. Fanatisme Dan Fanatisme, dalam majalah Gempita, tahun 1, no. 1, 15 Maret $1955^{18}$

d. Abdullah Ubaid Sebagai Pendidikan, dalam Suluh NU, Agustus 1941, tahun ke-1 No. $5 .{ }^{19}$

e. Kemajuan Bahasa Berarti Kemajuan Bangsa, dalam Suara Ansor, Rajab 1360 Th. IV No. 3, ditulis dengan nama Banu Asy'ari. ${ }^{20}$

f. Pendidikan Ketuhanan, dalam Mimbar Agama Tahun 1 No. 5-6, 17 Nopember - 17 Desember $1950 .^{21}$

${ }^{14}$ Achmad Zaini, K.H Abdul Wahid Hasyim Pembaru Pendidikan Islam (Jombang : Pesantren Tebuireng, 2011), hlm. 41-42.

${ }^{15}$ Diantara tiga keputusan itu adalah : (1) Atas usul K.H. Abdul Wahid Hasyim sebagai Mentri Agama, kabinet mengeluarkan Peraturan Pemerintahn tanggal 20 Januari 1951 yang mewajibkan pendidikan dan pengajaran agama dalam lingkungan sekolah-sekolah umum, baik negri maupun swasta. (2) Ia mendirikan sekolah guru hakim agama di Malang, Banda Aceh, Bandung, Bukit Tinggi dan Yogyakarta. (3) Ia mendiriksn pendidikan guru agama negeri di Tanjung Pinang, Bandung, Pamekasan dan Salatiga. Muhammad Rifa'I, Wahid Hasyim Biografi Singkat 1914-1953, hlm. 39.

${ }^{16}$ Aboebakar Atjeh, Sejarah Hidup KH. Abdul. Wahid Hasyim (Jombang Jawa Timur : Pustaka Tebuireng, 2015), hlm. 754-756.

${ }^{17}$ Ibid., hlm. 757-764.

${ }^{18}$ Ibid., hlm. 824-825.

${ }^{19}$ Ibid.,hlm. 860-865.

${ }^{20}$ Ibid.,hlm. 866-870.

${ }^{21}$ Ibid.,hlm. 871-874. 
g. Perguruan Tinggi Islam, Pidato menyambut berdirinya Universitas Islam Sumatra Utara di Medan 21 Juni $1952 .{ }^{22}$

h. Tuntutan Berpikir, dalam kata pendahuluan agenda Kementrian Agama $1951-1952 .^{23}$

\section{Rumusan Masalah}

1. Apa saja nilai-nilai pendidikan karakter dalam perspektif K.H Abdul Wahid Hasyim ?

2. Bagaimana relevansi nilai-nilai pendidikan karakter K.H. Abdul Wahid Hasyim dengan pendidikan karakter bangsa?

\section{Tujuan Penelitian}

1. Untuk mengetahui nilai-nilai pendidikan karakter dalam perspektif $\mathrm{KH}$. Abdul Wahid Hasyim.

2. Untuk mengetahui relevansi nilai-nilai pendidikan karakter K.H. Abdul Wahid Hasyim dengan pendidikan karakter bangsa.

\section{Manfaat Penelitian}

1. Memberikan wawasan baru tentang nilai-nilai pendidikan karakter dalam perspektif KH Abdul Wahid Hasyim.

2. Hasil penelitian ini diharapkan menjadi salah satu sumbangan pemikiran dari penulis yang merupakan wujud aktualisasi diri sebagai insan akademik yang bergelut dalam dunia pendidikan Islam.

\section{Tinjauan Pustaka}

Tinjauan pustaka atas hasil penelitian terdahulu yang relevan dengan penelitian penulis diantaranya ;Pertama,tesis Moh. Ismail, mahasiswa Program Pascasarjana UIN Sunan Ampel Surabaya, tahun 2014, dengan judul Pemikiran Pendidikan Islam KH. Abdul Wahid Hasyim.Hasil dari tesis ini menunjukkan bahwa pada dasarnya pemikiran pendidikan KH.Abdul Wahid Hasyim memberi hak semua orang untuk mengambil keputusan dan juga memandang semua orang mempunyai posisi yang setara. Oleh sebeb itu, dalam pendidikan Islam harus ada yang namanya kebebasan, penghormatan akan martabat orang lain, ada persamaan dan juga harus dapat menjamin tegaknya keadilan. KH.Abdul Wahid Hasyim berusaha menghadirkan konsep pendidikan Islam yang demokratis yang bisa memberikan kesempatan kepada semua siswa untuk terlibat langsung dalam mengembangkan kemampuannya, sehingga bisa menjadi manusia yang kritis dan kreatif. $^{24}$

\footnotetext{
${ }^{22}$ Ibid.,hlm. 875-877.

${ }^{23}$ Ibid.,hlm. 894-896.

${ }^{24}$ Moh. Ismail, Pemikiran Pendidikan Islam K.H. Abdul Wahid Hasyim, (Surabaya : Tesis UIN Sunan Ampel, 2014).
} 
Kedua, penelitian dalam jurnal pendidikan agama Islam Vol. IX, No. 1, Juni tahun 2012di tulis olehZainuddin Syarif dan Abdul Gaffardengan judul Pendidikan Multukulturalisme Tauhidiq dalam Pemikiran KH. Abdul Wahid Hasyim. Hasil dalam jurnal ini di jelaskan bahwa pendidikan multikulturalisme tauhidiq menurut $\mathrm{KH}$ Abdul Wahid Hasyim merupakan suatu sarana untuk mentransformasikan kesetaraan dan keadilan sosial melalui sebuah proses pembelajaran berdasarkan kebudayaan dalam arti luas. Bukti tentang sebuah dedikasi pendidikan multikulturalisme tauhidiq KH. Abdul Wahid Hasyim, mampu mewujudkan persatuan dan kesatuan bangsa Indonesia secara utuh yang dimulai dari Pondok Pesantren Tebuireng. Landasan itu, berdasar atas butir-butir nilai kebangsaan, kebhinekaan, nasionalisme yang terkandung dalam dasar ideologi Negara, yang merupakan bagian dari hasil kerja keras ijtihad yang beliau telurkan bersama dengan pejuang bangsa lainnya. ${ }^{25}$

\section{Metodologi Penelitian}

Penelitian ini merupakan studi pustaka atau library research, yaitu studi penelaahan terhadap berbagai buku, literatur-literatur, catatan-catatan, dan laporan-laporan yang ada hubungannya dengan masalah yang dipecahkan. ${ }^{26}$ Penelitian ini memakai teknik pengumpulan data dokumentasi, yaitu pengumpulan data yang bersumber dari dokumen-dokumen atau catatancatatan berupa buku, jurnal, artikel, gambar, atau elektronik yang tersediaguna memperoleh berbagai informasi-informasi yang berkaitan dengan objek penelitian. ${ }^{27}$

\section{HASIL DAN PEMBAHASAN}

\section{Nilai-nilai Pendidikan Karakter KH. Abdul Wahid Hasyim}

Terdapat dua belas nilai karakter yang terintegrasi dalam pemikiran $\mathrm{KH}$. Abdul Wahid Hasyim. Dua belas nilai karakter tersebut dijelaskan dalam uraian berikutini :

\section{Nilai Religius}

Sebagai seorang ulama' KH.Abdul Wahid Hasyim adalah seorang yang sangat taat dalam beragama, segala ucapan dan tingkah lakunya berdasarkan ajaran dan pedoman agama (Islam). Nilai karakter religius beliau tercermin pada pidato pembukaan perayaan Maulid Nabi Muhammad Saw, di Istana Negara pada 2 Januari 1950 yang berjudul "Nabi Muhammad dan Persaudaraan Manusia". Bagi K.H Abdul Wahid Hasyim agama dihadirkan ke muka bumi ini adalah untuk kebaikan seluruh penghuninya karena didalam agama diajarkan bagaimana menolong satu sama lain. K.H Abdul Wahid Hasyim juga berpendapat,

\footnotetext{
${ }^{25}$ Zainuddin Syarif dan Abdul Gaffar, Pendidikan Multukulturalisme Tauhidiq dalam Pemikiran KH. Abdul Wahid Hasyim, Jurnal Pendidikan Agama Islam,Vol. IX, No. 1, Juni 2012.

${ }^{26}$ SuharsimiArikunto,Prosedur Penelitian Suatu Pendekatan Praktis, (Jakarta: Rineka Cipta, 2002), hlm. 34 .

${ }^{27}$ Moh. Nazir, Metode Penelitian, (Bogor: Ghalia Indonesia, 2005), hlm. 111.
} 
bahwa konteks kelahiran Nabi Muhammad Saw sebenarnya bukan hanya untuk umat Islam saja, melainkan untuk seluruh umat manusia. Di dalamnya mengajarkan bagaimana sikap tolong menolong antar sesama manusia, menjauhkan sikap benci dan menganjurkan untuk saling memaafkan satu sama lain.

Sebagai seorang pendidik, K.H Abdul Wahid Hasyim merupakan pribadi yang patut dijadikan tauladan, K.H Saifuddin Zuhri ${ }^{28}$ menuliskan dalam suratnya tertanggal 13 April 1957 tentang pribadi K.H Abdul Wahid Hasyim :

“... Kepada murid-murid dan pembantu-pembantunya.Almarhum K.H Abdul Wahid Hasyim senantiasa mendidik dengan sungguhsungguh, baik dengan nasihat-nasihat maupun dengan contoh perbuatan.Diberinya kesempatan bagi murid-muridnya untuk menyelesaikan sesuatu, sambil diberinya petunjuk-petunjuk seperlunya, lalu dituntunnya murid yang sedang diasuh itu.Kejadian semacam ini tidak hanya sekali dua, akan tetapi untuk seterusnya, untuk berbilang bulan dan tahun. "29

2. Nilai Toleransi

Sikap toleransi antar umat beragama dalam hubungan sosial diajarkan oleh K.H Abdul Wahid Hasyimmelalui pidatonya ketika pendirian Universitas Islam Sumatra Utara di Medan 1952, yang berjudul "Perguruan Tinggi Islam":

“...Suatu hal yang menggembirakan didalam pembukaan Perguruan Tinggi Islam ini perlu saya catat disini, bahwa walaupun Perguruan Tinggi yang diresmikan ini memakai nama suatu agama tertentu, yaitu Islam, tetapi di antara tenaga-tenaga yang memajukannya, baik di kalangan pengajar maupun di kalangan pelajarnya, terdapat orang-orang dari macam-macam golongan agama. Kiranya ini suatu permulaan yang baik bagi kebebasan pikiran dari ikatanikatan perasaan yang timbul karena perbedaan kepercayaan dan agama. Maka patutlah dikemukakan harapan disini, bahwa perasaan harga menghargai dan kerja sama yang baik itu, dapat dipelihara selanjutnya. Bukan saja dalam batas lingkungan Perguruan Tinggi Islam ini, akan tetapi kiranya dapat pula disebarluaskan keluar dan diisikan kepada pelajar-pelajar dan siswa-siswa untuk generasi yang akan datang. "30

\footnotetext{
${ }^{28}$ Syaifuddin Zuhri merupakan anak asuh didikan dari K.H Abdul Wahid Hasyim.Sebagai seorang pendidik K.H Abdul Wahid Hasyimdapat mengkader Syaifuddin Zuhri sampai menduduki jabatan Mentri Agama RI tahun 1962-1967. Lebih lengkap kisah perjuangan hidup Syaifuddin Zuhri bersama K.H Abdul Wahid Hasyim, lihat di Syaifuddin Zuhri, Guruku Orang-Orang Dari Pesantren (Yogyakarta : Pustaka Sastra LKiS, 2012).

${ }^{29}$ H. Aboebakar Atjeh, Sejarah Hidup K.H Abdul Wahid Hasyim, hlm. 313.

${ }^{30}$ K.H Abdul Wahid Hasyim, "Perguruan Tinggi Islam" Pidato Mentri Agama K.H Abdul Wahid Hasyim, dalam menyambut berdirinya Universitas Islam Sumatra Utara, di Medan, 21 Juni 1952, dalam H. Aboebakar Atjeh, Sejarah Hidup KH. Abdul. Wahid Hasyim, hlm. 877.
} 
Dalam pidato tersebut K.H Abdul Wahid Hasyim mengajarkan umat Islam untuk saling bertoleransi dengan pemeluk agama lain. Menghargai hubungan emosional antara satu dengan yang lain. Dan tetap menekankan kerja sama walaupun berbeda kepercayaan atau agama. Hal itu mengisyaratkan bahwa adanya perbedaan bukan berarti akan munculnya perpecahan. Sebaliknya perbedaan merupakan suatu rahmat.Sikap toleransi terhadap pemeluk agama lain merupakan sikap yang luhur serta dapat memupuk rasa persatuan antar manusia yang berbeda agama.

3. Nilai Disiplin

Tidak ada kesuksesan tanpa displin yang tinggi, begitu juga dengan sejarah kehidupan K.H Abdul Wahid Hasyimyang penuh dengan kedisiplinan yang tinggi dalam melaksanakan aktifitasnya baik dalam kehidupan keluarganya maupun dalam jajaran birokrasi yang dia pimpin. Adapun kedisiplinan yang terdapat pada pribadi K.H Abdul Wahid Hasyim, sebagaimana di kemukakan oleh Murtahjijah Ahmad wakil ketua PB NU Muslimat sebagai berikut:

“...waktu Masyumi mengadakan kursus kadernya di Bendungan, dan pada waktu itu saya mengikuti kursus sampai selesai, sedangkan Pak Abdul Wahid Hasyim adalah salah seorang yang mengajar di kursus itu. Seperti kesannya, Pak Abdul Wahid Hasyim bukanlah tipe pekerja kantor yang suka menjalankan jam karet. Ia selalu datang tepat waktu dalam sebuah pertemuan kursus, sehingga sering kali justru para pengikut kursus telat karena K.H Abdul Wahid Hasyim selalu datang pada waktu yang ditetapkan." 31

Ungkapan diatas menunjukkan bahwa KH.Abdul Wahid Hasyim adalah sosok pribadi yang selalu menerapkan sikap disiplin waktu dalam setiap aktifitas beliau.

4. Nilai Kerja Keras

Tidak ada kesuksesan tanpa kerja keras, kata itu yang dapat menggambarkan dalam sejarah kehidupan sehari-hari KH.Abdul Wahid Hasyim baik dalam meningkatkan kompetensi diri ataupun untuk memberikan sumbangsih terhadap kemerdekaan Republik Indonesia (RI).Kerja keras K.H Abdul Wahid Hasyim ini diwujudkan tidak hanya untuk diri pribadinya melainkan juga untuk kepentingan Republik Indonesai. Kerja keras untuk diri pribadinya ditunjukkan dengan kesungguhannya dalam belajar secara otodidak, belajar di pondok pesantren dan madrasah, kemudian dilanjutkan dengan menimba ilmu di kota suci Makkah. Sedangkan untuk kepentingan Republik Indonesia,

\footnotetext{
${ }^{31}$ Aboebakar Atjeh, Sejarah Hidup KH. Abdul. Wahid Hasyim, hlm. 299-300. Lihat juga Muhammad Rifa'I, Wahid Hasyim Biografi Singkat 1914-1953, cet.ke-1 (Yogyakarta : Ar-Ruzz Media Group, 2009), hlm.148.
} 
perjuangannya dimulai sejak sebelum Proklamasi Kemerdekaan, ia termasuk pemimpin yang aktif berjuang menegakkan kemerdekaan tanah airnya.Bahkan banyak pikiran dan usaha mengenai perjuangan dan pembentukan negara berasal darinya.Ia menyatakan bergabung dan mendukung sepenuhnya kepada Republik Indonesia. Sejak saat itu K.H Abdul Wahid Hasyim memimpin dalam berbagai jabatan penting dalam kabinet Kementrian Agama Republik Indonesia. ${ }^{32}$

\section{Nilai Mandiri}

Kehidupan KH Abdul Wahid Hasyim tidak begitu lama, hanya sekitar 39 tahun, namun ia telah memiliki catatan sejarah yang hebat dan berbagai jabatan yang ia duduki, mulai dari mentri negara sampai dengan jabatan menteri agama, yang menunjukkan bahwa dalam kehidupannya telah terdapat nilai-nilai mandiri.Dalam bidang pendidikan K.H Abdul Wahid Hasyim mempromosikan reformis pendidikan dan menekankan pentingnya pendidikan bagi anak demi menciptakan generasi mandiri. ${ }^{33}$ Penanaman karakter mandiri terdapat dalam tulisan K.H Abdul Wahid Hasyim yang berjudul "Abdullah Ubaid Sebagai Pendidik". Tulisan tersebut dimulai dengan menceritakan bagaimana K.H Abdul Wahid Hasyim menerima tamu bernama Abdullah Ubaid bersama dua orang putranya yang masih anak-anak. Anak yang pertama berumur tujuh tahun dan yang kedua berumur lima tahun. Dalam pertemuan tersebut kemudian terjadilah cerita pendidikan sederhana, tetapi bermakna tinggi ketika sang tuan rumah menyediakan minuman teh dan sang tamu, terutama anaknya, hendak meminumnya.

"Ketika itu si anak yang kecil meminta diberi minum teh, bapaknya (Abdullah Ubaid) kemudian berkata kepada anaknya, "Ini air teh yang engkau minta itu sudah tersedia, minumlah!." Si anak berkata bahwa airnya masih panas.Sang ayah menjawab, "Tuangkanlah ke piring cangkir. Si anak menyatakan bahwa ia takut nanti jika air tehnya tumpah. Maka, si ayah menjawab "Tumpah pun tidak apaapa, toh tuan rumah yang mempunyai teh ini tidak akan marah. Bukankah begitu saudara (kepada K.H Abdul Wahid Hasyim beserta keluarga)?" sang tuan rumah menjawab, "Tidak masalah".Setelah itu, si anak kemudian menuangkan air tehnya ke piring dan menunggu beberapa lamanya, kira-kira air teh itu sudah dingin, maka katanya kepada ayahnya."Bapak, tolonglah, minumkan air teh ini kepada saya."Sang ayah menjawab, "Minumlah sendiri, engkau sudah pintar meminum, jangan takut akan tumpah." Si anak menjawab, menyatakan "jika tertumpah tentu akan jadi kotor pakaianku, jika kotor nanti akan diganti yang bersih (memang ketika

\footnotetext{
${ }^{32}$ KH. A. Wahid Hasyim, Sejarah Pemikiran dan Baktinya bagi Agama dan Bangsa, editor, Shofiyullah Mz (Yogyakarta : Pesantren Tebuireng, 2011), hlm. 182.

${ }^{33}$ Ibid., hlm. 156.
} 
itu ada membawa pengganti pakaian)". Akhirnya air teh itu diminumnya dan tidak sedikit pun yang tertumpah."34

Mengenai tulisan K.H Abdul Wahid Hasyim diatas, K.H Saifuddin Zuhri berpendapat bahwa kisah sederhana tersebut amat penting artinya bagi seorang guru maupun bagi seorang ayah atau ibu.Kepada anak harus ditanamkan kepercayaan pada dirinya sendiri, dimulai dari pekerjaanpekerjaan yang kecil dan mudah. Guru maupun orang tualah yang harus membangkitkan semangat berani berbuat sambil diberikan petunjuk agar dapat dikerjakan dengan baik. Hal demikian sangatlah penting bagi perkembangan mental anak. ${ }^{35}$

6. Nilai Demokratis

K.H Abdul Wahid Hasyim adalah sosok pribadi yang memiliki karakter yang demokratis.Karakter demokratis tersebut diajarkan oleh KH.Abdul Wahid Hasyim melalui tulisannya yang berjudul "Tuntutan Berfikir".

"....Sedemikian kerasnya Islam mengajarkan berpikir secara demoktratis dengan menggunakan logika dan mantik, sehingga dalam al-Qur'an sendiri banyak dimuat kritik-kritik orang pada Nabi Muhammad SAW. Umpamanya seperti "Wayalaquuluuna innahuu lamajnuun". Mereka itu mengatakan bahwa Nabi Muhammad itu adalah gila, termuat dalam al-Quran, untuk menunjukkan pada kaum muslim bahwa diantara manusia ada yang bersikap lancang... dimaksud untuk memberikan pelajaran bahwa makian-makian demikian tidak akan merugikan, kecuali pada orang yang mengeluarkan sendiri dan bahwa pada akhirnya toh, akal dan pikirkannlah yang akan mendapat kemenangan. Dan perasaan serta sentiment adalah merugikan bagi orang yang mengandungnya sendiri, lebih banyak daripada bagi orang yang dibencinya. "36.

Melalui tulisan diatas K.H Abdul Wahid Hasyim mengajarkan bagaimana umat Islam agar dapat berpikir secara demokratis namun tidak lepas dari logika dan mantik (ilmu berargumen).K.H Abdul Wahid Hasyim juga menegaskan bahwa Islam tidak mengenal kata ta'ashshub(fanatisme). Islam memang benar-benar demokratis, tidak takut pada pendapat orang lain yang berbeda haluan. Bahkan dia beriktikad bahwa tidak ada buku yang lebih demokratis dari pada alQur'an.Di dalam al-Qur'an termuat ayat “ $W a$ yaquuluuna innahu lamajnuun” (yang dimaksud mereka lawan Nabi Muhmmad, mengatakan

${ }^{34}$ K.H Abdul Wahid Hasyim, “Abdullah Oebayd Sebagai Pendidik” Suluh NU, Agustus 1941, Th.1 No.5, dalam H. Aboebakar Atjeh, hlm. 860.

${ }^{35}$ Syaifuddin Zuhri, Guruku Orang-Orang Dari Pesantren, (Yogyakarta : Pustaka Sastra LKiS, 2012),hlm. 180.

${ }^{36}$ K.H Abdul Wahid Hasyim, "Tuntutan Berfikir”, Kata Pendahuluan Agenda Kementrian Agama, 1951-1952, dalam H. Aboebakar Atjeh, Sejarah Hidup KH. Abdul. Wahid Hasyim, hlm.895. 
bahwa sesungguhnya Muhammad itu adalah gila). ${ }^{37}$ Bagi KH. Abdul Wahid Hasyim, ayat tersebut dipertontonkan al-Qur'an pada umat Islam dengan pengharapan supaya mereka dapat melihat, bahwa otak manusia itu ada juga yang demikian tololnya meraka kehabisan hujjah (argument) didalam bertukar pikiran lalu memakai kata-kata kotor dan maki-makian.

7. Nilai Kreatif

Nilai kreatifitas KH.Abdul Wahid Hasyim dapat dilihat dari gagasannya tentang pembaruan sistem pendidikan dipesantren Tebuireng. Dalam pembaruan pesantren tersebut K.H Abdul Wahid Hasyim mengusulkan untuk mengubah sistem pembelajaran klasikal dengan sistem pembelajaran tutorial,yang merupakan metode modern, menyenangkan dan dinamis, dengan tujuan untuk menumbuh kembangkan budaya kritis para santri, ${ }^{38}$ serta mendirikan Madrasah Nidzamiyah yang memasukkan materi pelajaran umum ke pesantren, dimana $70 \%$ kurikulumnya berisi materi pelajaran umum dan 30\% nya berisi materi pelajaran agama. Dari penjelasan tersebut dapat dipahami bahwa, gagasan pembaruan pesantren yang dilakukan oleh KH. Abdul Wahid Hasyim merupakan salah satu bentuk kreatifitas beliau dalam bidang pendidikan, hal itu sebagai bentuk kesadaran akan tantangan masyarakat yang semakin berkembang disatu sisi, dan kondisi intelektualitas masyarakat Muslim, terutama yang terwakili oleh kelompok "sarungan" di sisi lain.

8. Nilai Semangat Kebangsaan

Perwujudan dari nilai semangat kebangsaan KH. Abdul Wahid Hasyim, dia tunjukkan tatkala memperjuangkan bentuk dan dasar Negara Indonesia dalam sidang BPUPKI (Badan Penyelidikan Usaha-usaha Persiapan Kemerdekaan Indonesia). Sebagai perwakilan dari kalangan Nasionalis Islam K.H Abdul Wahid Hasyim mengajukanusulan penting yaitu : presiden harus orang Islam, serta mencanangkan Islam sebagai agama negara karena mengingat Islam adalah mayoritas penduduk Indonesia. Dilain pihak, kalangan Islam menyodorkan Piagam Jakarta yang akhirnya disetujui oleh dua kelompok Nasionalis Islam dan Sekuler. Namun pada tahap berikutnya, tepat sehari sebelum Proklamasi K.H Abdul Wahid Hasyim berubah pikiran, ia menerima usulan kaum nasionalis sekuler dengan mendukung penghapusan tujuh kata dalam Mukaddimah UUD yang dikenal dengan sebutan Piagam Jakarta

${ }^{37}$ K.H Abdul Wahid Hasyim, "Fanatisme Dan Fanatisme”, Gempita No. 1 tahun ke-1, 15 Maret 1955, dalam H. Aboebakar Atjeh, Sejarah Hidup KH. Abdul. Wahid Hasyim, hlm. 824. Lihat juga dalam tulisan beliau yang berjudul "Perbaikan Perjalanan Haji" Mimbar Agama Tahun 1, No. 2, 17 Agustus 1951, dalam H. Aboebakar Atjeh, hlm. 950.

${ }^{38}$ KH. A. Wahid Hasyim, Sejarah Pemikiran dan Baktinya bagi Agama dan Bangsa, editor, Shofiyullah Mz, hlm. 39. 
(....kewajiban Menjalankan Syariat Islam bagi Pemeluk-pemeluknya $)^{39}$, padahal pada awalnya K.H Abdul Wahid Hasyim begitu getol memperjuangkan tujuh kata tersebut. Pemikiran K.H Abdul Wahid Hasyim yang demikian bukanlah merupakan pemikiran yang inkonsisten, melainkan disinilah letak kebesaran jiwa seorang K.H Abdul Wahid Hasyim, dia menempatkan kepentingan bangsa diatas kepentingan lain. ${ }^{40} \mathrm{Hal}$ tersebut merupakan wujud dari sikap semangat kebangsaan yang tinggi.

9. Nilai Cinta Tanah Air

Sebagai wujud sikap cinta tanah air, K.H Abdul Wahid Hasyim sangat menjunjung tingginya Bahasa Indonesia, Ia menanamkan karakter yang paling ringan yakni cinta terhadap bahasa. Bagi K.H Abdul Wahid Hasyim kemajuan bahasa juga merupakan kemajuan bangsa. Sebagaimana dalam tulisannya yang berjudul "Kemajuan Bahasa, Berarti Kemajuan Bangsa", dia menyayangkan pemudapemuda kota lebih bangga menggunakan bahasa asing dalam menegur sapa dengan koleganya dari pada menggunakan bahasa sendiri. Mereka yang menggunakan bahasa asing tersebut hanyalah alasan prestisius saja, parahnya mereka mulai tidak menjunjung rasa bangganya terhadap Bahasa Indonesia.Seharusnya sebagain bangsa Indonesia yang cinta terhadap tanah air, bahasa yang digunakan adalah bahasa Idonesia. Berikut yang diungkapkan K.H Abdul Wahid Hasyim dengan menggunakan nama pena Banu Asy'ari :

"Bagi orang yang berdiam diam di kota atau yang acap kali berkunjung ke kota, niscaya akan membenarkan perkataan penulis ini: Bukankah kerap kali benar, ia bahkan boleh dikata saban pagi sebagain dari kaum muda kita,... senang mengucapkan kaliamat "Good Morning" atau "Goeden Margen" dan entah Good apa lagi, dari pada melafalkan selamat pagi. Teristimewa kalaw bertemu dengan seorang kawannya, seolah-olah berat, tak kuasa dan bagaikan kelu lidahnya apakala ditegur dengan apa kabar? Sedang wajahnya membayang muram; tetapi bilamana ditegur "How Do You Do?atau "How Hoe Maak Je't? Riangnya bukan main dan seketika itu juga dijawab dengan lancar dan fasih, seakan-akan tiada merasa berat dan kemalasannya hilang seketika! (ganjilbukan?!). Nah sekianlah perbedaan bahasa kita dengan bahasa asing itu. Hanyalah sebagian bukti bahwasanya kemajuan bahasa itu berarti kemajuan bangsa, dan bukanlah keterangan

39 Dalam Mukaddimah UUD 1945 terdapat kata-kata "Berdasarkan kepada Ketuhanan, dengan kewajiban menjalankan syariat Islam bagi pemeluk-pemeluknya." Mengenai mukaddimah UUD tersebut kelompok nasionalis sekuler keberatan dengan adanya tujuh kata yang berbunyi "dengan kewajiban menjalankan syariat Islam bagi pemeluk-pemeluknya."

${ }^{40}$ Lebih lengkapnya mengenai penjelasan ini, dapat dibaca di buku yang Shofiyullah Mz, KH. A. Wahid Hasyim, Sejarah Pemikiran dan Baktinya bagi Agama dan Bangsa, hlm. 213-299. 
penulis yang demikian itu berarti penuh berkehendak merendahkan pada mereka yang tergila-gila barat, itu bukan, pun bukanlah berarti bahwasanya penulis benci atau tiada setuju dengan orang yang berbahasa asing itu sekali-kali bukan. Penulis senang kepada orang yang belajar bahasa asing dan setuju juga, kecuali termasuk kewajiban sebagai putera Timur yang Muslim, yang diharuskan menuntut akan sekian kepandaian yang ada diatas dan ilmu pengetahuan yang beraneka ragam itu, pun penulis pernah juga belajar sekalipun hanya satu ONE dua ONE atau se-EEN dua EEN, tetapi dalam selama kita belajar itu, kita harus tetap mempunyai anggapan dan kepercayaan bahwasanya kita putera Indonesia. Kita mempunyai bahasa sendiri, sedang kita belajar bahasa asing itu hanya sekedar untuk mengetahui belaka, tidak lain!!!... ${ }^{41}$

10. Nilai Bersahabat / Komunikatif

Sikap bersahabat dan komunikatifK.H Abdul Wahid Hasyim dia tunjukkan kepada siapapun. Tidak perduli orang tersebut muslim ataupun non-Muslim.Iadapat bergaul dengan berbagai macam kalangan, mulai dari pejabat, pemuda, petani, kondektur, sopir dan lainnya. K.H Abdurrahman Wahid (anaknya) memberikan kesaksian atas sikap ayahnya yang begitu mempunyai hubungan baik dengan berbagai kalangan :

"Perhatian Bapak yang besar bukan hanya kepada keluarga, Beliau juga bersikap demikian kepada setiap orang dan juga memiliki hubungan yang sangat baik dengan berbagai kalangan. Kawankawannya bukan hanya dari kalangan Muslim saja, melainkan nonMuslim..., "42

Sikap bersahabat kepada semua kalangan itu disertai dengan sikapnya yang tidak membeda-bedakan orang.Aisyah Hamid Baidlowi putri K.H Abdul Wahid Hasyim mengakuinya, bahwa Ayahnya mempunyai sikap yang demikian.Saat ada tamu dari siapapun baik itu mentri, Kiai, ketua partai, tetangga, sopir dan sebagainya semua diterima dengan baik.bahkan yang lebih mengagumkan adalah sikap santun K.H Abdul Wahid Hasym kepada sopirnya yang bernama Usman, dia memanggilnya dengan sapaan Bang Usman tidak Usman saja. $^{43}$

\section{Nilai Gemar Membaca}

"Membaca, membaca, membaca.Itulah kegemaran utama K.H Abdul Wahid Hasyim sejak kecil. Dia terus membaca meskipun harus berkorban memakai kacamata baca sejak usia 12 tahun. Ia tidak

${ }^{41}$ K.H Abdul Wahid Hasyim, "Kemajuan Bahasa Berarti Kemajuan Bangsa”, menggunakan nama pena Banu Asy'ary, suara Ansor, Rajab 1360, Th. IV No.3, dalam H. Aboebakar Atjeh, hlm.867-868.

${ }_{42}$ Ali Yahya, Sama Tapi Berbeda Potret Keluarga Besar KH. Abdul Wahid Hasyim (Jombang: Yayasan K.H A. Wahid Hasyim, 2007), hlm.80.

${ }^{43}$ Ibid.,hlm. 86. 
mengenal lelah membaca banyak masalah. ${ }^{44}$ Penanaman nilai karakter gemar membaca ini, ia contohkan ketika menjadi kepala Madrasah Nidzamiyah. Ia mendirikan organisasi Ikatan Pelajar Islam (IKPI) yang dipimpinnya sendiri, kemudian membangun perpustakaan sebuah taman bacaan yang menyediakan tidak kurang dari 500 buah kitab bacaan untuk anak-anak dan pemuda. Selain itu, ia juga berlangganan surat kabar dan majalah dari berbagai terbitan.Karakter gemar membaca penting untuk terus dibumikan, karena indek yang di riles UNESCO tahun 2011 bahwa gemar membaca masyarakat Indonesia hanya berkisar $0,001 \%$ artinya hanya sekitar satu dari 1000 penduduk Indonesia yang serius membaca. ${ }^{45}$ Padahal membaca merupakan kunci mendapatkan ilmu.Oleh karena itu meniru rekam jejak K.H Abdul Wahid Hasyim dalam dunia pendidikan merupakan langkah tepat untuk meningkatkan ilmu pengetahuan, terlebih diterapkan dalam pendidikan.

12. Nilai Rasa Ingin Tahu

KH.Abdul Wahid Hasyi dikenal sebagai seorang pembelajar tanpa kenal waktu dan tanpa melihat tempat.Selalu ada rasa ingin tahu dalam dirinya.Rasa keingintahuan KH. Abdul Wahid Hasyim terhadap ilmu pengetahuan amat kuat, beliau rajin membaca bahkan berlangganan beberapa jurnal dan majalah dalam aksara latin dan Arab. ${ }^{46}$ Menurut cerita yang dituturkan oleh KH Syaifuddin Zuhri, KH Abdul Wahid Hasyim juga merupakan pelanggan tetap sebuah perpustakaan di kota Surabaya. Tidak seperti orang kebanyakan yang datang keperpustakaan dengan memilih judul yang telah disiapkan dari rumahnya, KH A. Wahid Hasyim membaca buku apa saja tanpa memilih judul. Beliau mengambil secara berurutan, buku-buku yang tersusun di rak hingga seluruh buku habis dibacanya.Selain mempelajari aksara latin, rasa keingintahuan K.H Abdul Wahid Hasyim pun berlanjut dengan mempelajari beberapa bahasa asing yaitu bahasa Inggris dan Belanda. Beliau memperdalam bahasa tersebut secara otodidak dengan membaca Sumber Pengetahuan yang waktu itu masih bernama Majalah Tiga Bahasa. ${ }^{47}$

\section{Relevansi Nilai Pendidikan Karakter KH. Abdul Wahid Hasyim dengan Pendidikan Karakter Bangsa.}

Berdasarkan analisis penulis, dari dua belas nilai pendidikan karakter yang telah diuraikan diatas memiliki relevansi dan kesesuaian dengan pendidikan

\footnotetext{
${ }^{44}$ Buntaran Sanusi, dkk. (ed), K.H Abdul Wahid Hasyim, Mengapa Memilih NU ? Konsepsi tentang Agama, Pendidikan dan Politik (Jakarta : Inti Sarana Aksara, 1985) hlm. 1

${ }^{45} \mathrm{http} / / /$ surabayanews.co.id/2016/05/17/59565/sedih-minat-baca-masyarakat-indonesia-ternyatasegini.html diakses pada hari selasa, 02 Mei 2016, pukul 21.00 wib.

${ }^{46}$ H. Aboebakar Atjeh, Sejarah Hidup KH. Abdul Wahid Hasyim, hlm, 162.

${ }^{47}$ K. H Abdul Wahid Hasyim : Sejarah, Pemikiran dan Baktinya bagi Agama dan Bangsa, editor Shofiyullah Mz, hlm. 147.
} 
karakter bangsa.Di mulai dari nilai Religius.Nilai religius inimerupakan nilai yang menjadi landasan dalam bersikap dan bertindak.Dalam berbagai tulisan, pemikiran serta perjalanan hidupnya, K.H Abdul Wahid Hasyim selalu mengkaitkannya dengan nilai keagamaan (Islam).Posisi K.H Abdul Wahid Hasyim sebagai ulama mempertegas nilai karakter religius beliau. Nilai ini sejalan dengan yang disampaikan Sudrajat bahwa pendidikan karakter adalah sebuah sistem yang menanamkan nilai-nilai karakter pada peserta didik, mengandung komponen pengetahuan, kesadaran individu, tekat serta adanya kemauan dan tindakan untuk melaksanakan nilai-nilai, baik kepada Tuhan Yang Maha Esa, diri sendiri, sesama manusia, lingkungan maupun bangsa sehingga akan terwujud insan kamil. ${ }^{48}$

K.H Abdul Wahid Hasyim juga menanamkan nilai-nilai sosial seperti toleransi, demokratis, bersahabat/komunikatif sebagai acuan dalam bertingkah laku dalam berinteraksi dengan sesama. ${ }^{49}$ Dengan nilai-nilai sosial yang diajarkan oleh K.H Abdul Wahid Hasyim, Ia ingin menyampaikan pesan bahwa sesungguhnya manusia adalah bersaudara satu sama lain. Nilai persaudaraan bagi K.H Abdul Wahid Hasyim merupakan tata cara manusia dalam pertemanan, apakah itu kepada antar negara, atau kepada orang yang terdiri dari berbagai latar belakang bahkan kepada orang yang berprofesi dibawahnya. K.H Abdul Wahid Hasyim menyadari bahwa bangsa Indonesia adalah bangsa yang multikultural. Disamping itu dia memberikan teladan agar selalu berlaku baik kepada siapa saja meskipun kepada anak buahnya, seperti apa yang diungkapkan oleh anaknya bernama Aisyah Hamis Baidhlowi, "K.H Abdul Wahid Hasyim bila menyapa sopirnya dia memanggilnya dengan nama bang Usman". ${ }^{50}$ Selain itu, dalam hubungan sosial K.H Abdul Wahid Hasyim menekankan sikap toleransi yang merupakan sikap saling menghormati orang yang berkeyakinan (agama) tidak sama. Apa yang menjadi nilai-nilai sosial dalam pendidikan karakter K.H Abdul Wahid Hasyim tersebut tertuang dalam tujuan pendidikan karakter yang berusaha membangun kehidupan kebangsaan yang multikultural. ${ }^{51}$

Selain nilai pendidikan karakter religius dan sosial, K.H Abdul Wahid Hasyim juga mengajarkan nilai karakter berkewarganegaraan. Dalam nilai karakter kewarganegaraan, Ia menekankan nilai-nilai semangat kebangsaan dan cinta tanah air. Dengan nilai tersebut, bagi K.H Abdul Wahid Hasyim merupakan cara untuk memajukan bangsa. Dalam menempatkan nilai karakter cinta tanah air, Ia menanamkan karakter yang paling ringan yaitu cinta terhadap bahasa. Sehingga K.H Abdul Wahid Hasyim berkesimpulan kemajuan bahasa adalah

48 Nurla Isna Aunillah, Panduan Menerapkan Pendidikan Karakter di Sekolah (Yogyakarta : Laksana, 2011), hlm. 19. Lihat juga di Akhmad Sudrajad, "Tentang Pendidikan Karakter", dalam http://akhmadsudrajad.wordpress.com/2010/08/20/pendidikan-karakter-di-smsp, diakses pada tanggal 17 Mei 2016, pukul 08.45 WIB.

${ }^{49}$ Zubaedi, Desain Pendidikan Karakter Konsepsi dan Aplikasi Dalam Lembaga Pendidikan (Jakarta : Kencana, 2011), hlm. 209.

${ }^{50}$ Ali Yahya, Sama Tapi Berbeda Potret Keluarga Besar KH. Abdul Wahid Hasyim, hlm. 86.

${ }^{51}$ Tim Penyususn, Buku Panduan Pelaksanaan Pendidikan Karakter (Jakarta : Kementrian Pendidikan Nasional Badan Penelitian Dan Pengembangan Pusat Kurikulum Dan Perbukuan, 2011), hlm. 7. 
kemajuan bangsa.Bagaimana tidak, dia mencontohkan Hilter dan Chamberlain ketika bernegosiasi menggunakan bahasa negara mereka masing-masing meskipun keduanya sama-sama menguasai bahasa lawannya.Dengan mencintai bahasa merupakan bukti kita mencintai tanah air kita. ${ }^{52}$ Kemudian semangat kebangsaan K.H Abdul Wahid Hasyim tunjukkan dengan tatkala mengedepankan kepentingan bangasa dari pada pendapat pribadinya dalam sidang BPUPKI.Ia menyetujui untuk mengamandemenkan tujuh kata yang diperdebatkan dalam sidang tersebut. Adapun kata yang diamandemenkan tersebut adalah "dengan kewajiban menjalankan syariat Islam bagi pemelukpemeluknya". Apa yang menjadi nilai-nilai kewarganegaraan dalam pendidikan karakter K.H Abdul Wahid Hasyim ini juga terdapat dalam rumusan tujuan pendidikan karakter pada poin membangun sikap warganegara yang mencintai damai, kreatif, mandiri, dan mampu hidup berdampingan dengan bangsa lain dalam suatu harmoni. ${ }^{53}$

Nilai pendidikan karakter yang terakhir yang ditanamkan oleh K.H Abdul Wahid Hasyim adalah nilai karakter pengembangan diri.Karakter tersebut diantaranya adalah nilai, disiplin, mandiri, kerja keras, gemar membaca, rasa ingin tahu dan kreatif. Melalui nilai-nilai tersebut merupakan cara untuk mengembangkan potensi pribadi anak didik, membentuk jiwa-jiwa yang kuat serta memiliki kebaikan untuk berbuat yang lebih baik lagi. Dengan karakter mandiri dan kerja keras, bagi K.H Abdul Wahid Hasyim anak didik dapat mampu menghadapi pekerjaan yang sulit dan pada akhirnya tidak mudah minta bantuan terhadap orang lain, anak didik berusaha kerja keras semampunya guna menyelesaikan pekerjaannya. Mengenai karakter gemar membaca dan rasa ingin tahu ini merupakan wujud dari karakter cinta pada ilmu pengetahuan. Mengenai nilai karakter pengembangan diri tersebut relevan dengan apa yang menjadi tujuan pendidikan karakter yakni membangun potensi diri dan peradaban bangsa yang cerdas, berbudaya luhur, dan mampu berkontribusi terhadap pengembangan kehidupan umat manusia, mengembangkan potensi dasar agar berhati baik, berpikir baik dan berprilaku serta keteladanan baik. ${ }^{54}$

K.H Abdul Wahid Hasyim merupakan konseptor pendidikan Islam yang ulung.Gagasan-gagasan serta pemikirannya yang penulis analisis melalui nilainilai pendidikan karakter masih relevan dengan pendidikan karakter bangsa. Mengenai relevansi gagasan pendidikan K.H Abdul Wahid Hasyim, Dhofir mengatakan bahwa madrasah-madrasah serta pondok pesantren modern saat ini yang memadukan antara ilmu agama dengan ilmu umum merupakan pegembangan gagasan dari prototype Madrasah Nidzamiyah yang menjadi pilot projeck K.H Abdul Wahid Hasyim dalam mengembangkan pesantren Tebuireng.

\footnotetext{
${ }^{52}$ K.H Abdul Wahid Hasyim, “Kemajuan Bahasa Berarti Kemajuan Bangsa”, hlm. 867-868.

${ }^{53}$ Tim Penyususn, BukuPanduan Pelaksanaan Pendidikan Karakter, hlm. 7.

${ }^{54}$ Ibid.., 7.
} 


\section{KESIMPULAN}

Dalam membentuk manusia yang mulia dan bangsa yang bermartabat salah satu upaya yang dilakukan adalah melalui pendidikan karakter, dengan berusaha menanamkan karakter yang bernafaskan nilai agama. Melalui penanaman pendidikan karakter ini diharapkan dunia pendidikan akan menjadi motor penggerak dalam membangun karakter peserta didik dan anggota masyarakat pada umumnya, sehingga memiliki kesadaran kehidupan berbangsa dan bernegara yang kuat, berakhlak, berprinsip dan bermartabat dengan mempertimbangkan norma-norma agama dan budaya masyarakat. Berdasarkan analisis yang penulis lakukan terhadap pemikiran pendidikan karakter KH Abdul Wahid Hasyim, ditemukan dua belas nilai yang berusaha ditanamkan oleh beliau (KH Abdul Wahid Hasyim).Dua belas nilai tersebut diantaranya ; nilai religius, nilai toleransi, nilai disiplin, nilai kerja keras, nilai mandiri, nilai demokrasi, nilai kreatif, nilai semangat kebangsaan, nilai cinta tanah air, nilai bersahabat/komunikatif, nilai gemar membaca, dan nilai rasa ingin tahu. Indikator nilai pendidikan karakter tersebut dilihat dari kepribadian beliau yang sangat fenomenal dan berbagai perjuangan beliau, baik perjuangan melalui dunia pendidikan, melalui organisasi, melalui tulisan artikel dan pidato-pidatonya.

Adapun nilai-nilai pendidikan karakter yang di ajarkan oleh KH Abdul Wahid Hasyimsejalan dengan tujuan pendidikan karakter bangsa yakni membangun kehidupan kebangsaan yang multikultural, membangun peradaban bangsa yang cerdas, berbudaya luhur, dan mampu berkontribusi terhadap pengembangan kehidupan umat manusia, mengambangkan potensi dasar agar berhati baik, berpikiran baik, dan berprilaku baik serta keteladanan baik, membangun sikap warganegara yang mencintai damai, kreatif, mandiri, dan mampu hidup berdampingan dengan bangsa lain dalam suatu harmoni.

\section{SARAN}

Demi keberhasilan dalam pelaksanaan pendidikan karakter ini, bagi seorang guru, haruslah mempunyai integritas dan dedikasi yang kuat ketika menjadi transformer bagi siswa atau santrinya.Perwujudan integritas dedikasi ini, terutama dalam pendidikan karakter, haruslah disesuaikan dengan nilai-nilai kebaikan universal, atau dalam konteks ke Indonesiaan adalah multikultural.Bagi keluarga, terutama orang tua sebagai figur panutan anak yang pertama dan juga masyarakat yang menjadi lingkungan anak harus membantu efektifitas pendidikan karakter dengan ikut serta menanamkan nilai-nilai kebaikan yang universal sejak dini.Bagi pemerintah sebagai pegayom warganya, perlunya melakukan sosialisasi kepada seluruh komponen pelaksana pendidikan baik (keluarga, masyarakat maupun sekolah) tentang pentingnya menanamkan pendidikan karakter berdasarkan nilai agama.Dan bagi pesantren sebagai lembaga pendidikan, harus selalu dapat menyesuaikan dengan zaman, berprinsip mempertahankan tradisi lama yang baik dan mengambil tradisi baru yang lebih baik. 


\section{DAFTAR PUSTAKA}

Arikunto, Suharsimi, Prosedur Penelitian Suatu Pendekatan Praktis, Jakarta: Rineka Cipta, 2002.

Atjeh, Aboebakar, Sejarah Hidup KH. Abdul. Wahid Hasyim, Jombang Jawa Timur : Pustaka Tebuireng, 2015.

Aunillah, Nurla Isna, Panduan Menerapkan Pendidikan Karakter di Sekolah, Yogyakarta : Laksana, 2011

Azzet, Akhmad Muhaimimin, Urgensi Pendidikan Karakter di Indonesia, cet.ke-II, Yogyakarta : Ar-Ruzz Media, 2013.

Hasyim, Abdul Wahid "Kemajuan Bahasa Berarti Kemajuan Bangsa", menggunakan nama pena Banu Asy'ary, suara Ansor, Rajab 1360, Th. IV No.3.

Hasyim, Abdul Wahid, Sejarah Pemikiran dan Baktinya bagi Agama dan Bangsa, editor, Shofiyullah Mz Yogyakarta : Pesantren Tebuireng, 2011.

Hasyim, Abdul Wahid, "Abdullah Oebayd Sebagai Pendidik” Suluh NU, Agustus 1941, Th.1 No.5.

Hasyim, Abdul Wahid, "Perbaikan Perjalanan Haji" Mimbar Agama Tahun 1, No. 2, 17 Agustus 1951.

Hasyim, Abdul Wahid, "Perguruan Tinggi Islam" Pidato Mentri Agama K.H Abdul Wahid Hasyim, dalam menyambut berdirinya Universitas Islam Sumatra Utara, di Medan, 21 Juni 1952.

http://surabayanews.co.id/2016/05/17/59565/sedih-minat-baca-masyarakatindonesia-ternyata-segini.htm

Ismail, Moh.,Pemikiran Pendidikan Islam K.H. Abdul Wahid Hasyim, Surabaya : Tesis UIN Sunan Ampel, 2014.

Marimba, Akhmad D, Filsafat Pendidikan Islam, Bandung : Al-Ma'arif, 1962.

Nazir, Moh., Metode Penelitian, Bogor: Ghalia Indonesia, 2005.

Peraturan Pemerintah Republik Indonesia Nomor 55 Tahun 2007 Tentang Pendidikan Agama dan Keagamaan. 
Rifa'I, Muhammad, Wahid Hasyim Biografi Singkat 1914-1953, cet. ke 1, Yogyakarta : Ar-Ruzz Media Group, 2009.

Sanusi, Buntaran, dkk. (ed), K.H Abdul Wahid Hasyim, Mengapa Memilih NU ? Konsepsi tentang Agama, Pendidikan dan Politik (Jakarta : Inti Sarana Aksara, 1985

Sudrajad, Akhmad, "Tentang Pendidikan Karakter", http://akhmadsudrajad.wordpress.com/2010/08/20/pendidikan-karakterdi-smsp

Syarif, Zainuddin, dan Abdul Gaffar, Pendidikan Multukulturalisme Tauhidiq dalam Pemikiran KH. Abdul Wahid Hasyim, Jurnal Pendidikan Agama Islam,Vol. IX, No. 1, Juni 2012.

Tim Penyususn, Buku Panduan Pelaksanaan Pendidikan Karakter, Jakarta : Kementrian Pendidikan Nasional Badan Penelitian Dan Pengembangan Pusat Kurikulum Dan Perbukuan, 2011.

Undang-Undang Republik Indonesia Nomor 20 Tahun 2003 Tentang Sistem Pendidikan Nasional.

Wibowo, Agus, Pendidikan Karakter Berbasis Sastra, cet. ke-1, Yogyakarta : Pustaka Pelajar, 2013.

Yahya, Ali, Sama Tapi Berbeda Potret Keluarga Besar KH. Abdul Wahid Hasyim, Jombang: Yayasan K.H A. Wahid Hasyim, 2007.

Zaini, Achmad, K.H Abdul Wahid Hasyim Pembaru Pendidikan Islam, Jombang : Pesantren Tebuireng, 2011.

Zubaedi, Desain Pendidikan Karakter Konsepsi dan Aplikasi Dalam Lembaga Pendidikan, Jakarta : Kencana, 2011.

Zuhri, Syaifuddin, Guruku Orang-Orang Dari Pesantren, Yogyakarta : Pustaka Sastra LKiS, 2012. 